\title{
FAEDO-GALERKIN APPROXIMATE SOLUTIONS FOR NONLOCAL FRACTIONAL DIFFERENTIAL EQUATION OF SOBOLEV TYPE
}

\author{
Alka Chadha, D. Bahuguna and Dwijendra N. Pandey
}

\begin{abstract}
This paper studies a fractional differential equation of Sobolev type with nonlocal initial conditions in an arbitrary separable Hilbert space. We study the associated integral equation and then, consider a sequence of approximate integral equations obtained by projection of considered associated integral equation onto finite dimensional space. The sufficient condition for providing the existence and uniqueness of mild solution to every approximate integral equation is obtained via the techniques of Banach fixed point theorem and analytic semigroup theory. By utilizing the Faedo-Galerkin approximations, we establish some convergence results for approximate solutions. Finally, an example is given to explain the applicability of the discussed abstract results.
\end{abstract}

Mathematics subject classification (2010): 26A33, 34K37, 34K40, 34K45, 35R11, 45J05, 45K05.

Keywords and phrases: Analytic semigroup, Banach fixed point theorem, nonlocal conditions, fractional differential equation, Faedo-Galerkin approximations, Sobolev type differential equation.

\section{REFERENCES}

[1] B. Bonilla, M. Rivero, L. Rodriguez-Germa and J. J. Trujillo, Fractional differential equations as alternative models to nonlinear differential equations, Appl. Math. Comput. 187 (2007), $79-88$.

[2] K. S. Miller And B. Ross, An Introduction to the Fractional Calculus and Fractional Differential Equations, John Wiley and Sons, Inc., New York, 1993.

[3] S. G. Samko, A. A. Kilbas And O. I. Marichev, Fractional Integrals and Derivatives: Theory and Applications, Gordon and Breach Science Publisher, Yverdon, 1993.

[4] A. A. Kilbas, H. M. SRivastava And J. J. Trujillo, Theory and Applications of Fractional Differential Equations, Elsevier, Amsterdam, 2006.

[5] I. Podlubny, Fractional differential equations, Mathematics in Science and Engineering, vol. 198, Academic Press, San Diego (1999).

[6] L. BYSZEWSKI, Theorems about the existence and uniqueness of solutions of a semilinear evolution nonlocal Cauchy problem, J. Math. Anal. Appl. 162 (1991) 497-505.

[7] L. BYSZEWSKI, V. LAKSHMIKANTHAM, Theorem about the existence and uniqueness of a solution of a nonlocal abstract Cauchy problem in a Banach space, Applied Analysis 40 (1990) 11-19.

[8] K. BALAChANDRAN AND J. Y. PARK, Sobolev type integro-differential equation with nonlocal conditions in Banach spaces, Taiwanses J. Math. 7 (2003), 155-163.

[9] K. BALACHANDRAN AND M. ChANDRASEKARAN, Existence of solutions of a delay differential equation with nonlocal condition, Indian J. Pure Appl. Math. 27 (1996), 443-449.

[10] S. Agarwal and D. Bahuguna, Existence of solutions to Sobolev-type partial neutral differential equations, J. Applied Math. Stoch. Anal. 2006 (2006), pp. 10.

[11] F. Li, J. LiAng AND H. K. XU, Existence of mild solutions for fractional integro-differential equations of Sobolev type with nonolocal conditions, J. Math. Anal. Appl. 391 (2012), 510-525.

[12] B. RADHAKRISHNAN, A. MOHANRAJ AND V. VinOBA, Existence of solutions for nonlinear impulsive neutral integro-differential equations of Sobolev type with nonlocal conditions in Banach spaces, Elect. J. Diff. Equ. 2013 (2013), pp. 13. 
[13] M. FEČKAN, J. R. WANG AND Y. ZHOU, Controllability of fractional intergro-differential equations of Sobolev type with nonlocal conditions, J. Optim. Theo. Appl. 156 (2013), 79-95.

[14] J. R. WANG, M. FeČKAN AND Y. ZHOU, Controllability of sobolev type fractional evolution systems, Dyn. Part. Diff. Equ. 11 (2014), 71-87.

[15] M. Kerboua, A. Debbouche And D. Baleanu, Approximation controllability of Sobolev type nonlocal fractional stochastic dynamic systems in Hilbert spaces, Abst. Appl. Anal. 2013 (2013), pp. 10.

[16] B. RADHAKRISHNAN, A. MOHANRAJ AND V. VinOBA, Existence of nonlinear neutral impulsive integro-differential evolution equations of Sobolev type with time varying delays, J. Nonlinear Anal. Optimiz. 4 (2013), 205-218.

[17] N. I. MAhmUdov, Approximate controllability of fractional Sobolev type evolution equations in Banach spaces, Abst. Appl. Anal. 2013 (2013), pp. 9.

[18] A. Debbouche And J. J. Nieto, Sobolev type fractional abstract evolution equations with nonlocal conditions and optimal multi-controls, Applied Math. Comp. 245 (2014), 74-85.

[19] M. Kerboua, A. Debbouche And D. Baleanu, Approximate controllability of Sobolev type fractional stochastic nonlocal nonlinear differential equations in Hilbert spaces, Elect. J. Qualit. The. Diff. Equ. 2014 (2014), 1-16.

[20] M. El-BoraI, Some probability densities and fundamental solutions of fractional evolution equations, Chaos Solitons Fractals 14 (2002), 433-440.

[21] Y. ZHOU AND F. JiAO, Existence of mild solutions for fractional neutral evolution equations, Comp. Math. Appl. 59 (2010), 1063-1077.

[22] F. Li AND G. M. N'GUÉRÉKATA, An existence result for neutral delay integro-differential equations with fractional order and nonlocal conditions, Abs. Applied Anal. 2011 (2011), pp. 20.

[23] A. PAZY, Semi-groups of Linear operator and Applications of Partial Differential Equations, Springer Verlag, 1983.

[24] R. Göthel, Faedo-Galerkin approximation in equations of evolution, Math. Meth. Appl. Sci. 6 (1984), 41-54.

[25] P. D. Miletta, Approximation of solutions to evolution equations, Math. Methods Appl. Sci. 17 (1994), 753-763.

[26] D. Bahuguna, S. K. SRIVAstaVa, Approximation of solutions to evolution integrodifferential equations, J. Applied Math. Stoch. Anal. 9 (1996), 315-322.

[27] D. Bahuguna, M. Muslim, Approximation of solutions to non-local history-valued retarded differential equations, Appl. Math. Comp. 174 (2006), 165-179.

[28] D. Bahuguna, Shruti Agarwal, Approximations of solutions to neutral functional differential equations with nonlocal history conditions, J. Math. Anal. Appl. 317 (2006), 583-602.

[29] M. Muslim, A. K. NANDAKUMARAn, Existence and Approximations of solutions to some fractional order functional integral equation, J. Integral Equ. Appl. 22 (2010), 95-114.

[30] A. ChADHA AND D. N. PANDEY, Existence, uniqueness and approximation of solution for the fractional semilinear integro-differential equation, Int. J. Applied Math. Stat. 52 (2014), 73-89.

[31] A. Chadha And D. N. PAndey, Approximations of solutions for a Sobolev type fractional order differential equation, Nonlinear Dyn. Sys. The. 14 (2014), 11-29.

[32] A. ChADHA AND D. N. PANDEY, Existence and approximation of solution to neutral fractional differential equation with nonlocal conditions, Comp. Math. Appl. 69 (2015), 893-908. 